\title{
Articulação oracional e produção escrita: um trabalho com o pronome relativo
}

\author{
Edvaldo Balduino Bispo* \\ UFRN \\ Maria Estela Lima da Costa Amurim** \\ UFRN
}

Recebido em: 09/06/2019

Aceito em: 08/11/2019

Resumo: Descrevemos e analisamos trabalho empreendido em turma do ensino fundamental, com foco no emprego do pronome relativo em situação de escrita monitorada. Objetivamos fazer os alunos aprimorarem o uso adequado desse recurso linguístico para fins de articulação de porções textuais. Por meio de uma pesquisa interventiva, de natureza qualitativa, desenvolvemos sequência didática composta por oito atividades. A intervenção ancorou-se teórico-metodologicamente na Linguística Funcional norte-americana, particularmente na correlação dessa abordagem com o ensino de língua portuguesa. Como resultados, destacamos avanços dos alunos no emprego adequado do relativo em contexto de uso monitorado da língua em comparação à fase inicial da pesquisa.

Palavras-chave: Pronome relativo. Articulação oracional. Produção escrita. Linguística Funcional.

Abstract: We describe and an analyze a class activity developed with $9^{\text {th }}$ grade students of an elementary school focusing on the use of the relative pronoun in a situation of formal writing. The aim was to improve the use of this linguistic item by the students in order for them to articulate pieces of texts. A didactic sequence was developed through an interventional qualitative research. The theoretical and methodological support is the North American Functional Linguistics. As results, we highlight the students' progress regarding the adequate use of the relative pronoun in a formal context of language usage.

Keywords: Relative pronoun. Clause combining. Written texts. Functional Linguistics.

Resumen: Describimos y analizamos un trabajo hecho con un grupo de la enseñanza primaria (fundamental), con atención al empleo del pronombre relativo en una situación de escrita monitoreada. Objetivamos que los alumnos perfeccionen el uso adecuado de ese recurso lingüístico para la correcta articulación de porciones textuales. A través de una investigación intervencionista, de naturaleza cualitativa, desarrollamos una secuencia didáctica con ocho actividades. La intervención fue basada, teórico-metodológicamente, en la Lingüística Funcional norte-americana. Como resultados, destacamos los avances de los alumnos en el empleo adecuado del relativo en el contexto del uso monitoreado de la lengua.

Palabras clave: pronombre relativo. Articulación de la oración. Producción escrita. Lingüística Funcional. 


\section{Introdução}

Apresentamos, neste artigo, resultados de uma intervenção pedagógica realizada

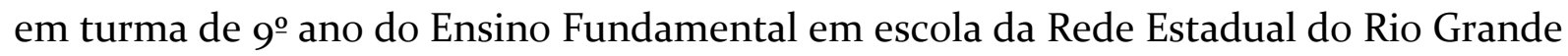
do Norte. A intervenção teve como objeto de estudo o pronome relativo (PR, daqui em diante), com foco em seu papel de articulador de porções textuais.

A necessidade, por parte dos alunos, de produzir texto escrito em situação de uso monitorado da língua, em especial por ocasião do processo seletivo para ingresso em instituto federal, serviu de motivação para o empreendimento da pesquisa aqui relatada. A produção de textos coerentes com ideias devidamente articuladas implica a mobilização de uma série de recursos, dentre os quais estão os mecanismos de coesão textual, como é o caso dos PR.

Figurando entre os elementos de coesão por substituição e por conexão, conforme Antunes (2005), o PR desempenha duplo papel: além de retomar um termo da oração anterior (seu antecedente), daí o caráter fórico, serve como elo subordinante da oração que introduz (caráter conectivo). Sua participação na articulação de porções textuais foi $\mathrm{o}$ aspecto mais relevante trabalhado na intervenção pedagógica desenvolvida. Nessa direção, as atividades realizadas buscaram, em última instância, o emprego adequado do PR em situação de escrita monitorada por parte dos sujeitos da pesquisa.

Nortearam o trabalho realizado os seguintes questionamentos: i) Quais os PR mais empregados nas produções escritas dos alunos/sujeitos da pesquisa e em que ocorrências são utilizados adequadamente? ii) Que fatores de natureza comunicativa e/ou cognitiva estão implicados na recorrência a um ou a outro PR? iii) Como um trabalho calcado na perspectiva funcional de ensino de língua pode contribuir para o uso adequado de PR por alunos de ensino fundamental em produções escritas?

A pesquisa teve como objetivo geral aprimorar o uso do PR por alunos do ensino fundamental em situação de escrita monitorada, com vistas à ampliação da competência comunicativa. Especificamente, objetivou: i) mapear os PR empregados em produções escritas dos alunos bem como o uso adequado desse emprego; ii) identificar fatores cognitivos e/ou comunicativos envolvidos na escolha de um ou de outro PR; iii) 
desenvolver uma ação pedagógica fundamentada na perspectiva funcional de ensino de língua, com foco no uso adequado do PR à situação de comunicação.

A intervenção empreendida fundamentou-se teoricamente em pressupostos da Linguística Funcional de vertente norte-americana, particularmente na correlação dessa abordagem com o ensino de língua, com base em Oliveira e Cezario (2007), Furtado da Cunha, Bispo e Silva (2014) e Oliveira e Wilson (2015), e em orientações curriculares nacionais (BRASIL, 1998).

O artigo compõe-se de cinco seções, incluindo a introdução. Na segunda delas, apresentamos as bases teóricas que sustentam o trabalho desenvolvido. Na terceira, contextualizamos o ambiente e os sujeitos envolvidos na pesquisa. Na seção seguinte, são demonstrados e discutidos os resultados da intervenção. Por fim, trazemos as considerações finais.

\section{Linguística Funcional e ensino de língua}

Nesta seção, caracterizamos a perspectiva teórica em que fundamentamos o trabalho realizado: a Linguística Funcional norte-americana. Explicitamos seus pressupostos básicos e algumas de suas categorias analíticas, particularmente os princípios de iconicidade e de marcação. Além disso, delineamos a abordagem do ensino de língua à luz do funcionalismo linguístico e a correlacionamos com diretrizes gerais para o ensino de língua portuguesa, conforme constam dos Parâmetros Curriculares Nacionais (BRASIL, 1998).

O Funcionalismo linguístico caracteriza-se por estudar a relação entre a estrutura gramatical das línguas e os diferentes contextos interacionais em que ela é usada. Assume o pressuposto básico de que a forma da língua resulta da função a que ela serve nas diversas situações de interação verbal. A relação forma-função é o fio condutor que norteia os trabalhos desenvolvidos sob essa perspectiva teórica. Dessa premissa fundamental advém a ideia de que a língua deve ser vista como um sistema adaptativo (DU BOIS, 1985) utilizado para fins de comunicação. Relacionadas a essa premissa estão a noção de que discurso e gramática interagem e se influenciam mutuamente e a visão 
de que a gramática resulta da cristalização ou regularização de estratégias discursivas recorrentes (FURTADO DA CUNHA; COSTA; CEZARIO, 2015). Dado que fatores cognitivos, comunicativos e culturais atuam na emergência, convencionalização e mudança do sistema linguístico (MARTELOTTA, 2011), a pesquisa funcionalista tem como ponto de partida dados empíricos de uso real da língua em textos falados e/ou escritos.

Entre princípios, processos e categorias analíticas do funcionalismo, destacaremos aqui a iconicidade e a marcação, utilizados para a discussão das ocorrências de PR nas atividades realizadas pelos alunos-sujeitos da pesquisa. Por iconicidade entende-se a correlação natural entre forma e função, entre o código linguístico (expressão) e seu designatum (conteúdo), com base na ideia de que a estrutura linguística reflete, de algum modo, a estrutura da experiência (GIVÓN, 1984). A partir daí, supõe-se que, pelo fato de a linguagem ser uma faculdade humana, as propriedades da conceitualização humana do mundo ou as propriedades da mente humana são reveladas pela estrutura linguística.

Conforme Givón (1984), o princípio da iconicidade se assenta em três subprincípios: a) o da quantidade, que relaciona o volume de informação à quantidade de forma para codificá-la, subentendendo-se que a complexidade do pensamento tende a ser representada pela complexidade da expressão (SLOBIN, 1980), de modo que o que é mais simples codifica-se em estruturas menos complexas; b) o da integração ou proximidade, que correlaciona a distância linear entre os elementos à distância conceptual entre as ideias por eles representadas, isto é, o que está cognitivamente próximo tende a ser codificado de maneira mais integrada; c) o da ordenação linear, o qual estabelece que os constituintes se ordenam, no tempo e no espaço, conforme pressões cognitivas. Desse modo, a iconicidade é estimulada por questões de clareza e transparência, de modo a reduzir a opacidade entre a forma linguística e seu correlato semântico e/ou pragmático.

Quanto ao princípio da marcação, ele está relacionado à presença, em um par contrastivo, de uma propriedade ausente no outro membro, considerado não marcado (FURTADO DA CUNHA, COSTA, CEZARIO, 2015). Segundo Givón (1990), existem três critérios principais que podem ser usados para distinguir uma categoria marcada de uma não marcada, num contraste binário: a) Complexidade estrutural - a estrutura marcada 
tende a ser mais complexa (ou maior) que a não marcada correspondente; b) Distribuição de frequência - a categoria marcada tende a ser menos frequente, portanto mais saliente cognitivamente, que a não marcada; c) Complexidade cognitiva - a estrutura marcada normalmente é mais complexa cognitivamente (em termos de atenção, esforço mental ou duração de processamento) que a correspondente não marcada.

Entender a gramática como um sistema aberto, suscetível a mudanças e afetado pelo uso que lhe é dado cotidianamente deveria ser condição obrigatória a todos os que assumem a tarefa de ensinar a língua a falantes dessa mesma língua. Isso porque é necessário desvendar as muitas facetas que ela apresenta, ou seja, a multiplicidade de usos que dela podemos fazer. Nessa direção, estudiosos funcionalistas reunidos em alguns grupos de pesquisa, como é o caso do Grupo de Estudos Discurso E Gramática (D\&G) vêm refletindo sobre as possibilidades de aplicação dos princípios e categorias funcionalistas no ensino de língua portuguesa. Com isso, foram produzidos vários trabalhos sobre diferentes aspectos gramaticais do português, nos quais se discutem a natureza, o alcance e as implicações da Linguística Funcional para a prática pedagógica, a exemplo de Furtado da Cunha e Tavares (2007, 2016), Bispo (2007), Oliveira e Cezario (2007), Furtado da Cunha, Bispo e Silva (2014), entre outros.

A perspectiva funcionalista de ensino de língua objetiva trabalhar questões linguísticas com base em seus propósitos discursivo-pragmáticos, vinculados a práticas sociais situadas. Essa proposta consubstancia-se nas atividades de análise e reflexão sobre a língua, por meio das quais se aprimoram as capacidades de compreensão e expressão dos alunos, isto é, sua competência comunicativa (FURTADO DA CUNHA, BISPO, SILVA, 2014). Nesse sentido, tal visão coincide com a proposta dos PCN de Língua Portuguesa, os quais destacam como um dos objetivos de ensino desse componente curricular:

possibilitar ao aluno utilizar a linguagem na escuta e produção de textos orais e na leitura e produção de textos escritos de modo a atender a múltiplas demandas sociais, responder a diferentes propósitos comunicativos e expressivos, e considerar as diferentes condições de produção do discurso (BRASIL, 1998, p. 32). 
Conforme pontuam Oliveira e Coelho (2008), o trabalho analítico e reflexivo sobre a língua tem como ponto inicial a observação das estruturas mais regulares verificadas no desempenho discursivo. Assim, o que se propõe é um trabalho que parta da investigação das estratégias recorrentes de expressão linguística, de modo a explicitar os princípios que regulam tais estratégias e que permitem a adequada interação entre os falantes da língua. Dessa forma, a orientação para o trabalho do professor, diferentemente da abordagem tradicional, não seria calcada na prescrição normativa, mas na observação de aspectos sociointeracionais e semântico-cognitivos implicados no uso da língua.

A abordagem funcionalista à língua(gem) também assume que as categorias linguísticas não possuem caráter discreto, mas que se constituem numa escalaridade, ou continuum, em que feixes de traços estão menos ou mais presentes. Ou seja, as fronteiras entre uma categoria e outra não são nítidas (FURTADO DA CUNHA, COSTA e CEZARIO, 2015). Essa abordagem proporciona ao professor a oportunidade de trabalhar um leque mais amplo de usos da língua e, assim, o aluno pode não só reconhecer diferentes possibilidades desses usos como formas legítimas, cada uma associada a situações comunicativas específicas, como também respeitar a diversidade linguística que caracteriza as comunidades de fala. Dessa forma, segundo registram Furtado da Cunha e, Bispo e Silva (2014), reitera-se a coincidência da perspectiva funcional com objetivos do ensino de língua portuguesa delineados nos PCN, assim explicitados:

- conhecer e valorizar as diferentes variedades do Português, procurando combater o preconceito linguístico;

- usar os conhecimentos adquiridos por meio da prática da análise linguística para expandir sua capacidade de monitoração das possibilidades de uso da linguagem, ampliando a capacidade de análise crítica (BRASIL, 1998, p. 33).

Em resumo, o ensino de língua que aqui defendemos corrobora orientações dos documentos oficiais de referência curricular nacional, no que tange (i) à diversidade de uso que fazemos da língua; (ii) ao papel dos contextos comunicativos e da interação na organização estrutural dos textos; (iii) ao desenvolvimento da competência comunicativa do aluno; (iv) ao respeito à pluralidade linguística que caracteriza nossas comunidades de fala. 


\section{Descrição da intervenção pedagógica}

Nesta seção, caracterizamos a intervenção pedagógica quanto ao ambiente em que foi desenvolvida, dos sujeitos participantes, do tipo de pesquisa empreendida, do método nela utilizado e dos procedimentos metodológicos, particularmente a descrição da sequência didática com a explicitação das atividades realizadas.

A ação pedagógica se deu em uma turma do $9^{\circ}$ ano do Ensino Fundamental, turno matutino, de Escola Estadual localizada em Parnamirim-RN. Os sujeitos participantes foram 30 alunos na faixa etária de 14 a 16 anos, todos novatos na série/ano, sendo 22 meninas e 8 meninos, além da professora de Língua Portuguesa, responsável pela pesquisa. Essa escola é referência na qualidade de ensino e reconhecida pela aprovação de seus alunos em exames para acesso ao ensino superior em instituições públicas e para ingresso em escolas federais de ensino médio profissionalizante.

A pesquisa caracteriza-se como de natureza eminentemente qualitativa e pode ser classificada como intervenção pedagógica, pois interfere diretamente e de forma planejada, no processo de aprendizagem dos sujeitos que dela participam, produzindo, assim, conhecimento intelectual. Esse aspecto é o que lhe concede status de trabalho investigativo. A intervenção pedagógica aproxima-se da pesquisa-ação, a qual tem relevante caráter pedagógico. Isso porque não se trata de um simples levantamento de dados, mas, sim, de um processo em que se dá o "conhecer”, implicando o envolvimento dos sujeitos participantes, que sempre têm algo a "dizer" e a "fazer". Nesse sentido, Damiani et al (2013) referem-se a outro ponto de convergência entre os dois tipos de pesquisa, apresentado por Thiollent (2011): a necessidade de diálogo com um referencial teórico, fundamental para a significação da pesquisa, uma vez que, limitada à ação, ela seria reduzida a ativismo. $\mathrm{O}$ autor ressalta, porém, que, diferentemente da pesquisaação, a interventiva, embora vise à promoção de avanços educacionais, não tem seu foco principal nos objetivos emancipatórios. Na primeira, todos os envolvidos participam ativamente - do planejamento à implementação; na segunda, os sujeitos-alvo contribuem com opiniões, sugestões e críticas, mas é o pesquisador quem identifica e decide como irá resolvê-lo.

Revista Investigações, Recife, v. 32, n. 2, p. 275 - 304, Dezembro/2019 
O empreendimento da intervenção aqui relatada deu-se por meio de uma sequência didática (SD), aqui entendida como "um conjunto de atividades escolares organizadas, de maneira sistemática, em torno de um gênero textual oral ou escrito” (DOLZ; NOVERRAZ; SCHINEWLY, 2004, p. 96). Numa visão mais abrangente desse procedimento, Kobashigawa et al. (2008, apud LEAL, 2013) coloca-o como um conjunto de atividades, estratégias e intervenções planejadas, etapa por etapa, pelo docente para que o alcance do entendimento do tema ou conteúdo seja possibilitado ao discente. As atividades que compuseram a SD foram diversificadas e envolveram desde o mapeamento e uso intuitivo do PR pelos alunos-sujeitos até a variação no emprego dos PR, implicando usos canônicos e usos não abonados pela tradição normativa.

A investigação dos usos do PR foi feita a partir da produção escrita de um artigo de opinião pelos alunos. A escolha por essa estrutura discursiva para o trabalho proposto se deveu ao fato de que, como diz Paredes Silva (1996 apud OLIVEIRA; WILSON, 2015, p. 106), ela está entre as que "repousam em unidades semânticas referentes à proposição, sintaticamente subordinadas”. Quando essas unidades são representadas por cláusulas adjetivas encabeçadas por um conector, essa conexão dá-se por um PR.

O trabalho teve início com a exibição do filme brasileiro Que horas ela volta?, de Anna Muylaert, cuja temática serviu de base à produção de um artigo de opinião. A proposta dessa produção escrita focalizava o preconceito social e teve como recorte o questionamento da relação entre condição social e capacidade intelectual.

Além da exibição do filme e discussão sobre seu conteúdo e da produção textual escrita, foram desenvolvidas outras atividades, quais sejam: uso intuitivo do pronome (indução ao emprego desse elemento), comparação entre diferentes estratégias de relativização, revisão coletiva de atividades anteriores e reescrita do artigo de opinião produzido inicialmente. No quadro a seguir, resumimos as atividades que compuseram a SD aplicada, apresentando breve descrição e objetivo(s).

Quadro 1: Caracterização geral das atividades da SD

\begin{tabular}{|l|l|l|}
\hline Atividade & Descrição geral & Objetivo(s) \\
\hline Exibição do & Exibição do filme para os alunos, & Proporcionar a apreensão \\
filme e & discussão de aspectos da temática por & de conteúdo para a \\
discussão sobre & ele tratada e socialização das & produção do artigo de \\
a temática & impressões/ opiniões dos alunos & opinião, que discutia um \\
& sobre questões feitas pela professora. & dos recortes temáticos de \\
\hline
\end{tabular}




\begin{tabular}{|c|c|c|}
\hline & & $\begin{array}{l}\text { caráter social veiculados } \\
\text { pelo filme. }\end{array}$ \\
\hline $\begin{array}{l}\text { Primeira } \\
\text { produção } \\
\text { escrita }\end{array}$ & $\begin{array}{l}\text { Produção de artigo de opinião com } \\
\text { base no conteúdo do filme exibido e } \\
\text { nas ideias socializadas no momento } \\
\text { da discussão. }\end{array}$ & $\begin{array}{l}\text { Viabilizar o mapeamento } \\
\text { dos PR utilizados pelos } \\
\text { alunos em situação de } \\
\text { escrita monitorada. }\end{array}$ \\
\hline $\begin{array}{l}\text { Uso intuitivo } \\
\text { de PR }\end{array}$ & $\begin{array}{l}\text { Emprego de recursos linguísticos, em } \\
\text { particular, PR, para articular porções } \\
\text { textuais cujo conteúdo dizia respeito } \\
\text { ao filme visto pelos alunos. Análise de } \\
\text { diferentes possibilidades de usos } \\
\text { desses recursos e dos efeitos de } \\
\text { sentido decorrentes de tais } \\
\text { possibilidades. Substituição de PR } \\
\text { usados excessivamente por outros } \\
\text { mecanismos de modo a garantir a } \\
\text { coesão de trecho fornecido em } \\
\text { exercício. }\end{array}$ & $\begin{array}{l}\text { Identificar os recursos } \\
\text { linguísticos utilizados } \\
\text { pelos alunos no lugar de PR } \\
\text { suprimidos dos trechos } \\
\text { originais; verificar se eles } \\
\text { percebem diferenças e } \\
\text { semelhanças entre o uso de } \\
\text { variados PR; observar se os } \\
\text { alunos usam } \\
\text { adequadamente os PR, se } \\
\text { eles conseguem eliminar o } \\
\text { uso excessivo desse } \\
\text { elemento e de que recursos } \\
\text { se valem para esse fim. }\end{array}$ \\
\hline $\begin{array}{l}\text { Comparação de } \\
\text { diferentes } \\
\text { estratégias de } \\
\text { relativização }\end{array}$ & $\begin{array}{l}\text { Cotejo entre diferentes estratégias de } \\
\text { relativização presentes em um texto } \\
\text { criado pela pesquisadora } \\
\text { especialmente para esse fim. Análise } \\
\text { da adequação ou não do uso dessas } \\
\text { estratégias. }\end{array}$ & $\begin{array}{l}\text { Comparar as estratégias de } \\
\text { relativização em termos } \\
\text { estruturais e de contextos } \\
\text { de uso. }\end{array}$ \\
\hline $\begin{array}{l}\text { Revisão } \\
\text { coletiva da } \\
\text { atividade sobre } \\
\text { uso de PR }\end{array}$ & $\begin{array}{l}\text { Revisão coletiva dos exercícios } \\
\text { propostos na terceira atividade. } \\
\text { Explanação sobre o uso de PR. }\end{array}$ & $\begin{array}{lr}\text { Esclarecer } & \text { dúvidas que os } \\
\text { alunos } & \text { apresentaram } \\
\text { durante a realização da } \\
\text { atividade } & \text { referida; } \\
\text { apresentar a visão da } \\
\text { gramática } & \text { tradicional } \\
\text { sobre os PR. } & \end{array}$ \\
\hline $\begin{array}{l}\text { Revisão } \\
\text { coletiva da } \\
\text { atividade sobre } \\
\text { estratégias de } \\
\text { relativização }\end{array}$ & $\begin{array}{l}\text { Revisão coletiva do exercício } \\
\text { proposto na quarta atividade. } \\
\text { Discussão sobre os usos das } \\
\text { diferentes formas de estruturação da } \\
\text { oração adjetiva. }\end{array}$ & $\begin{array}{l}\text { Refletir acerca das } \\
\text { possibilidades organização } \\
\text { da oração relativa e } \\
\text { associar cada possiblidade } \\
\text { a contextos de uso } \\
\text { específicos. }\end{array}$ \\
\hline $\begin{array}{ll}\text { Revisão de } \\
\text { artigos de } \\
\text { opinião } \\
\text { produzidos } \\
\text { pelos alunos }\end{array}$ & $\begin{array}{l}\text { Revisão coletiva de dois artigos de } \\
\text { opinião produzidos na atividade } 2 \text { da } \\
\text { SD. }\end{array}$ & $\begin{array}{l}\text { Identificar características } \\
\text { gerais do artigo de opinião; } \\
\text { observar a relevância do PR } \\
\text { no encadeamento } \\
\text { oracional do texto. }\end{array}$ \\
\hline $\begin{array}{l}\text { Segunda versão } \\
\text { do artigo de } \\
\text { opinião }\end{array}$ & $\begin{array}{l}\text { Reescritura do artigo de opinião } \\
\text { produzido na segunda atividade com }\end{array}$ & $\begin{array}{l}\text { Observar se os alunos } \\
\text { realizaram ajustes no } \\
\text { artigo com base nas }\end{array}$ \\
\hline
\end{tabular}

Revista Investigąçoes, Recife, v. 32, n. 2, p. 275 - 304, Dezembro/2019 


\begin{tabular}{|l|l|l|l|}
\hline $\begin{array}{l}\text { base na revisão coletiva feita na } \\
\text { atividade } 7 .\end{array}$ & $\begin{array}{l}\text { orientações da atividade de } \\
\text { revisão coletiva; verificar se } \\
\text { eles empregaram } \\
\text { adequadamente os PR na } \\
\text { articulação de porções } \\
\text { textuais. }\end{array}$ \\
\hline
\end{tabular}

Fonte: autoria própria

Essas oito atividades ${ }^{1}$ foram realizadas em 38 horas-aulas, sendo 26 no horário regular de aulas e 12 no contraturno. O tempo dedicado a cada uma delas foi o seguinte: 05 aulas para a primeira atividade; 02 para a segunda; 08 para a terceira; 02 aulas para a quarta; 10 aulas para a quinta; 05 para a sexta; 04 para a sétima; e 02 aulas para a última atividade.

Para efeitos de avaliação da intervenção realizada, foi feito o cotejo entre a primeira e a segunda versão do artigo de opinião para verificar possíveis avanços quanto à escrita do artigo de opinião e, em particular, quanto ao uso adequado de PR na articulação de partes do texto.

\section{Desenvolvimento da intervenção pedagógica e discussão dos resultados}

Conforme indicamos na seção anterior, a intervenção pedagógica se deu por meio de diversas atividades. Contemplamos, aqui, o relato dessas atividades e analisamos os resultados obtidos.

A primeira delas, a exibição do filme Que horas ela volta?, proporcionou à turma a apreensão e a socialização de ideias para posterior produção de um artigo de opinião. A mediação da professora-pesquisadora foi importante tanto para instigar os alunos a expressar opiniões sobre a temática tratada no filme e apresentar argumentos para sustentá-las quanto para avaliá-los em termos de pertinência e consistência. Houve grande participação da turma, de sorte que o objetivo pretendido foi alcançado.

\footnotetext{
${ }^{1}$ Nos anexos de 1 a 3, transcrevemos três das atividades aplicadas para que o leitor tenha uma melhor compreensão do tipo de trabalho realizado. Não anexamos todas por limitação de espaço.

Revista Investigações, Recife, v. 32, n. 2, p. 275 - 304, Dezembro/2019
} 
No que diz respeito à produção escrita, os alunos foram instados a escrever um artigo de opinião com base num recorte da temática do filme visto, qual seja: o questionamento sobre a possibilidade de um estudante de escola pública, nordestino e pobre, ingressar em universidade conceituada para fazer um curso considerado de elite. A atividade serviu para mapeamento de PR empregados pelos alunos e para identificação de usos adequados e não adequados desses elementos.

Com base nos textos produzidos, foi feito levantamento dos PR utilizados, ao fim do qual se chegou ao seguinte resultado: das 60 ocorrências, 53 foram com o relativo que, das quais o9 com esse elemento precedido do demonstrativo o; $03 \mathrm{com}$ o onde, sendo 02 sem antecedente explícito; o2 com cujo; o1 com quem; o1 com o qual. Vejamos estas ocorrências:

(1) "Conheço várias pessoas que eram pobres e hoje em dia tem condições [...] (Aluno 3)

(2) Por causa da classe social, do lugar onde mora ou até por causa da cor da pele. (Aluno 12)

(3) Sim, tudo isso é uma barreira para quem é humilde, mas, se a pessoa tentar, [...] (Aluno 8)

Os quantitativos aferidos corroboram pesquisas sobre orações relativas, a exemplo de Bispo (2009), as quais têm constatado maior frequência do que em relação aos demais PR. Essas pesquisas têm verificado também que esse pronome é empregado em quase todas as funções sintáticas e para retomar antecedentes de natureza semântica distinta (humanos e não humanos), sendo considerado relativo universal, conforme Bechara (2009), Castilho (2010) e Bagno (2011).

Em termos cognitivos, a maior frequência do que em relação aos demais PR pode ser explicada pelo princípio da marcação, conforme Bispo (2009). Segundo o autor, comparado aos demais PR, o que é menos complexo estruturalmente (é menor, possui menos massa fônica que os demais PR), é cognitivamente menos complexo em termos de demandar menos esforço mental (menos atenção e menor tempo de elaboração e de processamento) e, em decorrência, é mais frequente. Já o cujo e a forma o qual, por exemplo, com uma ocorrência apenas cada um, foram bem menos frequentes dada a maior complexidade estrutural e cognitiva. No caso de cujo, em particular, seu emprego demanda do falante/escrevente maior esforço cognitivo: implica dois referentes 
nominais, o estabelecimento de relação de pertencimento entre eles e, em relação ao subsequente, concordância em gênero e em número. Trata-se, assim, de um elemento bem marcado em comparação aos demais PR.

Associado a fatores cognitivos, o uso dos PR também tem motivação comunicativa. Tomemos, a título de ilustração, a forma o qual, que ocorreu precedida da preposição em (no qual) e em concomitância com o relativo que, conforme mostra o trecho a seguir.

(4) “...] ou seja é o empenho e o esforço do aluno que o diferencia dos demais, e mostra isso de novo no filme Que horas ela volta? que no qual mostra a filha de Val e que ela passou para a universidade [...]." (Aluno 19)

Essa construção sugere a (aparente) perda do caráter fórico do que, daí o emprego de outro relativo, com marca de gênero e número, como forma de recuperar, com mais precisão, o antecedente (o filme). Esse fato pode estar relacionado com o princípio da iconicidade (GIVÓN, 1990), pois, ao utilizar o no qual, o aluno deixa mais transparente a relação entre o PR e o elemento por ele retomado, evitando, assim, alguma incompreensão por parte do leitor. No caso em questão, o emprego de uma estrutura mais extensa (no qual), seguindo outro relativo (que) imprime mais clareza ao enunciado, o que resulta em maior expressividade comunicativa.

A análise de todas as ocorrências dos PR utilizados pelos alunos permitiu observar que, na maioria dos casos, esses elementos foram empregados adequadamente. Isso provavelmente se deveu a dois fatores: o que foi o mais recorrente e esses elementos desempenhavam função de sujeito e objeto direto.

Quanto à terceira atividade, os exercícios que a compuseram envolviam: i) o preenchimento de lacunas por PR, sem que se indicasse o elemento a ser utilizado; ii) a reflexão, por parte dos alunos, sobre os elementos por eles empregados, sobre a possibilidade de outros termos serem utilizados e sobre os efeitos de sentido decorrentes da escolha feita; iii) a comparação entre períodos conectados por PR e os equivalentes 
sem essa conexão; iv) a junção de orações para a formação de períodos compostos, com expectativa de uso de PR; v) a reescritura de texto para evitar repetição excessiva de PR.

Nos exercícios de preenchimento de lacunas, de onde foram retirados PR, os alunos, na maioria dos casos, atenderam às expectativas de respostas, fazendo uso predominante do relativo que. Dado que o preenchimento era intuitivo, podemos explicar esse fato com base no princípio da marcação e na universalização desse pronome, conforme discutido anteriormente. Já em relação às questões de reflexão sobre os elementos utilizados e possíveis substitutos, a maioria dos alunos não identificou o papel de articulador de orações desempenhado pelo PR.

No que diz respeito ao exercício de comparação entre trechos articulados pelo PR e trechos correspondentes sem essa ligação, os alunos conseguiram perceber a função do PR como elemento de coesão dentro das porções textuais analisadas, destacando que seu uso evitou repetição de palavras e tornou o texto mais “enxuto". A não repetição, aliás, foi o ponto central de outro exercício, no qual os alunos deveriam evitar a presença excessiva do relativo que. Com relação à parte da atividade 3 que envolvia a junção de orações para formação de períodos compostos, entretanto, a maioria dos alunos não atendeu às expectativas de respostas. Isso se deveu, principalmente, a dois aspectos: o fato de ser esperado o emprego de relativos mais marcados (o qual, quem, por exemplo); a demanda de preposição antes do PR, conforme a prescrição normativa. Assim, foram estruturadas orações adjetivas não canônicas, como a cortadora e a copiadora, ilustradas em (5) e (6), respectivamente.

(5) “... bonita piscina que Val nunca entrou.”

(6) “... bonita piscina que Fabinho e os amigos sempre tomavam banho nela."

A propósito, a atividade 4 consistiu na análise de formas diversas de organização da oração adjetiva (canônica e não canônicas), particularmente aquelas com o PR em função genitiva. Os alunos refletiram sobre as seguintes possibilidades de reunir as orações Bárbara explorava Val. e O prazer de Val era cuidar de Fabinho filho da patroa: 
(7) a. Bárbara explorava Val, que ela tinha o prazer de cuidar de Fabinho, filho da patroa.

b. Bárbara explorava Val, que o prazer era cuidar de Fabinho, filho da patroa.

c. Bárbara explorava Val, que o prazer dela era cuidar de Fabinho, filho da patroa.

d. Bárbara explorava Val, cujo prazer era cuidar de Fabinho, filho da patroa.

Dadas essas possibilidades e o contexto de uso (situação de sala de aula em que a professora solicitava a forma adequada de reunir as orações em questão), os alunos foram instados a refletir sobre: i) qual estrutura seria mais compreensível e por quê; ii) qual delas eles considerariam mais adequada à situação comunicativa; iii) possível diferença de sentido entre essas formas; e iv) outras maneiras de reunir as orações em foco. Esses aspectos se coadunam com pressupostos funcionalistas de que os usos linguísticos guardam estreita relação com demandas cognitivas e comunicativas, ajustando-se a tais demandas (GIVÓN, 1995; FURTADO DA CUNHA; COSTA; CEZARIO, 2015).

No cotejo das opções de articulação das orações apresentadas, a maioria dos alunos deu conta de que os casos que exemplificavam orações não canônicas (copiadora e cortadora), (7)a-c, representavam formas mais simples e fáceis de compreender, associadas à maior informalidade. Com relação à junção por meio de cujo, a maioria dos alunos a apontou como a "mais correta", "mais completa", "mais formal", "mais explicativa”, relacionando-a à formalidade, à norma culta. Nessa direção, as impressões dos alunos acerca das possibilidades de organização da relativa genitiva corroboram os achados de Bispo (2014a, b) quanto a motivações cognitivas e sociocomunicativas implicadas nos usos das estratégias de relativização. Segundo o autor, a forma canônica, no caso em questão, com uso de cujo, demanda maior custo cognitivo, ao passo que as estruturas copiadora $(7 a, c)$ e cortadora (7b) são mais expressivas e envolvem menor demanda de atenção e tempo de processamento.

No que concerne a outras formas de reunir as orações dadas, foram propostas variadas possibilidades, a exemplo de:

Revista Investigações, Recife, v. 32, n. 2, p. 275 - 304, Dezembro/2019 
(8) "Bárbara explorava Val, no qual o prazer dela era cuidar de Fabinho, filho da patroa.” (Alunos 4 e 27)

(9) "Bárbara explorava Val, a qual tinha o prazer de cuidar de Fabinho, filho da patroa." (Alunos 2 e 13)

(10) "Bárbara explorava Val, a empregada que tinha o prazer de cuidar de Fabinho, filho da patroa." (Alunos 12 e 25)

(11) "Bárbara explorava Val, ela tinha o prazer de cuidar de Fabinho, filho da patroa." (Alunos 6 e 22)

(12) "Bárbara explorava Val, que tinha o prazer de cuidar de Fabinho, filho da patroa." (Alunos 8 e 20)

(13) "Bárbara explorava Val. Sendo que o prazer de Val era cuidar de Fabinho, filho da patroa." (Alunos 5 e 30 )

As estruturas formuladas pelos alunos nesse item revelam que eles encontraram alternativas para a expressão de um mesmo conteúdo proposicional, apoiados nos diversos usos que o sistema linguístico possibilita. À exceção do equívoco observado em (8), pelo uso inadequado da preposição em seguida da forma o qual, fazendo referência ao termo feminino Val, todas as outras construções apontam para a adequação linguística. Em (9) e (12), há estruturas correspondentes ao modelo padrão da adjetiva, em que o PR (a qual, em [9] e que, em [12]) retoma o termo Val, na função nominativa de sujeito. Situação semelhante vemos em (10), em que os alunos empregaram o pronome numa relativa padrão, mas retomando o termo Val por meio do substantivo empregada, como recurso facilitador da expressão. Em (11), os alunos empregaram o pronome ela em vez do relativo.

A quinta atividade da SD foi dedicada à retomada dos exercícios da atividade 3. Foi a oportunidade de rever as respostas dadas pelos alunos e de cotejá-las com as expectativas. Nessa ocasião, foi feita uma revisão sobre PR e sobre seus usos, sendo destacado seu papel na articulação de porções do texto. Os alunos tiraram dúvidas sobre questões dos exercícios e puderam refazê-los. As aulas destinadas a essa parte da SD contou com bom engajamento da turma, o que contribuiu para tornar a atividade bastante produtiva. Foi possível aos alunos observar a funcionalidade do PR e perceber 
a existência de diferentes modos de organizar partes de um texto por meio desse recurso e de outros mecanismos linguísticos. O tipo de procedimento adotado sustenta-se na perspectiva funcionalista de ensino de língua, segundo a qual as questões linguísticas devem ser trabalhadas com base em seus propósitos discursivo-pragmáticos, vinculados a práticas sociais situadas (BISPO, 2009; FURTADO DA CUNHA; BISPO; SILVA, 2014).

Na atividade 6, foi feita a revisão coletiva dos exercícios referentes à comparação entre formas de organização da relativa genitiva, ilustradas em (4)a-d. Foi oportunizado aos alunos refletir sobre a coexistência de mais de uma estrutura linguística para um mesmo propósito comunicativo e a possibilidade de uso de cada uma delas considerando as situações de escrita, monitoradas ou sem necessidade de monitoramento. Necessário se fez explicação sobre os relativos e, em particular, sobre o cujo, com destaque às especificidades desse PR, a exemplo da relação por ele estabelecida entre o termo antecedente e o consequente. Associadas a essa explanação, foram tratadas questões relativas a usos linguísticos monitorados e não monitorados.

Para a atividade 7, também de revisão coletiva, foram escolhidos dois artigos de opinião produzidos na atividade 2. Esses textos são representativos do que a maioria dos alunos conseguiu fazer. Em linhas gerais, apresentam posicionamento dos autores sobre o questionamento feito na proposta de produção textual e expõem argumento(s). Nos artigos escolhidos, sustenta-se a ideia de que qualquer estudante é capaz de ingressar em uma universidade renomada, desde que haja interesse, esforço e dedicação. Evidencia-se, nos textos, a preocupação com o papel do governo, da escola e dos professores nessa escalada bem como a diferença que distancia as escolas públicas das escolas privadas quanto à estrutura física e à qualidade de ensino.

A revisão conjunta desses textos permitiu aos alunos observar características gerais do gênero artigo de opinião, identificar e solucionar alguns problemas linguísticos. Entre esses problemas, destacamos os implicados na coesão e na coerência textuais, com foco no encadeamento oracional por meio de PR. Consideramos esse momento da atividade bem proveitoso, pois os alunos puderam perceber, em textos mais próximos deles, alguns detalhes importantes até então desconhecidos ou desconsiderados por eles. Somado a isso, o fato de poderem interagir, questionando ou sugerindo maneiras de se chegar à melhor escritura, trouxe mais dinamicidade à aula, o que facilitou o desenvolvimento da atividade. A relevância desse tipo de trabalho é 
destacada por Oliveira e Coelho (2015), que, referindo-se à atividade de reescritura, assim se manifestam:

\begin{abstract}
Ao acrescentar, retirar, deslocar ou transformar porções ou termos da sequência textual, estão os alunos aprendendo a manipular não só a estrutura discursiva, mas também os sentidos, os conteúdos veiculados pela mesma, desenvolvendo individual e coletivamente sua capacidade de percepção dos artifícios ou recursos de linguagem a que todos estão submetidos numa comunidade linguística. (OLIVEIRA; COELHO, 2015, p. 82)
\end{abstract}

Cabe registrar, contudo, que a revisão feita não foi suficiente para dirimir todas as dificuldades apresentadas pelos alunos nos textos analisados. E mais, que havia nos textos de outros alunos problemas semelhantes ou que necessitavam de maior atenção, mas não houve como trabalhá-los dadas a diversidade de aspectos a serem abordados, a exiguidade de tempo e a demanda de questões implicadas no alcance da solução dos problemas detectados.

Como última atividade houve a reescrita do artigo de opinião produzido na atividade 2. Para a maioria dos alunos presentes, esse momento foi proveitoso, visto que eles tiveram a oportunidade de rever seu trabalho e tentar reorganizá-lo de acordo com as orientações repassadas nas aulas destinadas à revisão coletiva. Percebemos, porém, que, apesar da tentativa de deixar o texto mais adequado à exigência do gênero, muitos alunos não conseguiram fazê-lo como esperado.

Em termos de PR utilizados na segunda versão do artigo, também predominou o que, mas aumentou o uso de o qual. Esse aumento pode ser interpretado como ampliação do conhecimento por parte dos alunos quanto a esses elementos de conexão. Cabe mencionar que verificamos avanço quanto ao emprego adequado desses relativos, conforme ilustram (14)a-b e (15)a-b.

(14) a. "Mas o filho da patroa que estudava em escola boa tinha tudo que queria e não conseguiu passar." (Aluno 15, primeira versão)

b. "Porém o filho da patroa o qual estudava em escolas boas não conseguiu." (Aluno 15, versão final)

(15) a. "[...] o governo estabeleceu a lei de cotas, na qual facilita a sua entrada na universidade [...].” (Aluno 27, primeira versão) 
b. “[...] o governo estabeleceu a lei de cotas, a qual facilita a sua entrada na universidade [...].” (Aluno 27, versão final)

Esses registros nos mostram que o aluno, possivelmente, percebeu o papel do PR na articulação oracional e na coesão textual, bem como a necessidade de adequação do uso desse elemento linguístico à situação comunicativa. Na primeira versão de (14), o emprego do que em suas duas ocorrências provocou certa ambiguidade estrutural: possibilidade de o PR referir-se a filho ou a patroa; com a segunda versão, porém, pelo emprego de o qual, desfaz-se a possível ambiguidade e, por meio da retirada da segunda oração adjetiva, o aluno conseguiu deixar o texto mais conciso e coeso. No caso da primeira versão de (15), o aluno havia feito registro equivocado do relativo a qual, com função de sujeito, antecedido da preposição em. O trecho, que versava sobre os mecanismos de acesso de estudantes de escolas públicas à universidade, teve a inadequação resolvida com a retirada da preposição na versão final.

Houve, contudo, situação em que o PR foi utilizado inadequadamente tanto na primeira quanto na última versão do artigo. Foi o caso de cujo, conforme ilustrado em (16)a-b, ocorrências em que esse pronome foi empregado semelhantemente ao relativo que.

(16) a. "[...] a filha da empregada cujo estudava [...]." (Aluno 15)

b. “[...] essas pessoas cujo conseguiram [...].” (Aluno 21)

Podemos atribuir o uso inadequado de cujo ao desconhecimento das relações implicadas no emprego desse pronome, o que o torna bem marcado em relação aos demais PR. Ressaltamos, contudo, que também foi verificada estratégia alternativa ao emprego desse mesmo pronome, conforme mostrado em (17)a-b.

(17) a. "Não há dúvidas, que jovens cujo passaram maior parte de suas vidas estudando em escolas particulares possuem mais benefícios de que os que estudaram em escolas públicas [...]" (Aluno 2, primeira versão) 
b. "Não há dúvida que existe uma grande diferença entre as duas instituições e o governo consente essa diferença [...]"

Observe-se que, na segunda versão, o aluno se valeu de estratégia de esquiva para evitar o emprego de cujo, provavelmente por perceber que o uso na primeira versão não estava adequado e também talvez por ter dificuldade em utilizá-lo adequadamente. Notamos, assim, certa preocupação por parte dos alunos quanto ao uso de um ou de outro relativo em suas produções, em busca de maior adequação à situação de escrita a que foram submetidos.

Desenvolver uma intervenção pedagógica, tendo por fundamento a perspectiva funcional de ensino de língua, com ênfase no uso adequado do PR à situação de comunicação, foi um dos propósitos da pesquisa. A intervenção empreendida resultou positivamente, uma vez que possibilitou aos alunos, entre outros objetivos, (re)conhecer a importância de se analisarem elementos linguísticos com base na língua em funcionamento. Isso se deu no trabalho realizado a partir da aplicação do PR em textos autênticos e da análise desse elemento como articulador de porções textuais. Destacamos também como ponto positivo que o acesso aos diversos modos de organizar enunciados por meio de diferentes PR e a reflexão sobre cada modo, avaliando o PR no contexto de uso, trouxeram aos alunos a possibilidade de fazer escolhas por um ou outro relativo visando à adequação de seu emprego à situação comunicativa.

Nessa direção, outro aspecto relevante da pesquisa foi a evidência dada à variação linguística, especialmente pela consideração das estratégias de relativização, conforme Bispo (2007, 2014a, b). A atividade planejada para esse fim priorizou a relativa genitiva (KENEDY, 2014), nas formas canônica e não canônica, por meio das quais os alunos puderam refletir sobre diferentes modos de organizar enunciados e avaliá-los para posterior escolha entre uma ou outra forma de acordo com o contexto de interlocução. $\mathrm{Na}$ análise feita pelos alunos, as estratégias não canônicas (com destaque para a cortadora) foram avaliadas como as que apresentam maior possibilidade de uso por sua informalidade e simplicidade estrutural, o que pode facilitar a compreensão do conteúdo veiculado. A forma canônica com o uso de cujo foi avaliada pelos alunos como a mais formal, e alguns a consideraram mais “correta" porque é "mais culta”. Por fim, 
concluíram que todas as estratégias fazem sentido e podem ser usadas, respeitando-se o grau de (in)formalidade dos contextos comunicativos.

\section{Considerações finais}

A pesquisa aqui reportada teve como objetivo principal aprimorar o uso do PR em situação de escrita monitorada por alunos de ensino fundamental, visando à ampliação da competência comunicativa. Para esse intento, foi desenvolvida uma intervenção pedagógica com base numa sequência didática composta de oito atividades. Por meio dessas atividades, deu-se o mapeamento de PR empregados, a observação da adequação dos usos desse elemento linguístico em textos produzidos pelos sujeitos da pesquisa e foram analisados fatores cognitivos e comunicativos envolvidos no emprego dos PR.

Como resultado, em termos de PR empregados, constatamos uma frequência consideravelmente superior do que em comparação aos demais relativos e nas funções de sujeito e objeto direto em relação a outras funções. Essa maior ocorrência de que é explicada pelo princípio da marcação (GIVÓN, 1990), dado ser esse pronome menos ou não marcado cognitiva e estruturalmente em relação aos demais. No que diz respeito à adequação dos PR à situação comunicativa em que foram empregados, os alunos conseguiram fazê-lo com maior frequência na segunda versão do artigo de opinião. Situação particular, contudo, deu-se com o pronome cujo, utilizado inadequadamente, provavelmente por ser o mais marcado dos relativos, dada a complexidade implicada em seu uso: ligação entre os elementos antecedente e consequente e estabelecimento de relação de pertença entre eles.

Nas atividades de articulação de orações envolvendo o relativo em ambiente preposicionado e a análise de adjetivas genitivas codificadas por estratégias canônicas e não canônicas (cortadoras e copiadoras) de relativização, os alunos conseguiram: i) reunir orações por meio de PR adequados e pelo uso de mecanismos alternativos de articulação dessas orações; ii) perceber as relativas não canônicas como variantes possíveis na língua e passíveis de emprego em seus textos. A forma canônica, porém, foi 
tomada como a mais correta e a que seria mais empregada por eles. Esses achados se coadunam com pesquisas de Bispo (2009, 2014a, b) acerca de motivações para uso de estratégias de relativização.

$\mathrm{Na}$ versão final do artigo de opinião, foram identificados avanços relativos à redação do texto em si e, principalmente, ao emprego do PR e sua adequação à situação de escrita monitorada. Esses avanços foram notados, entre outras coisas, na preocupação por parte dos alunos em reorganizar sua escrita, demonstrando certo cuidado para encontrar a melhor forma de expressar as ideias e buscando o emprego adequado dos relativos, o que contribuiu para a inteligibilidade do texto. Assim, os sujeitos da pesquisa puderam perceber que o PR representa um recurso linguístico importante à construção de textos em que se exija tanto a devida articulação oracional quanto o estabelecimento da textualidade, garantindo a coesão e o alcance dos fins comunicativos.

O empreendimento da intervenção pedagógica relatada oportunizou uma reflexão, com base na prática docente, acerca de como a língua é tratada em algumas salas de aula das séries iniciais do ensino fundamental. Em algumas abordagens, prioriza-se o trabalho com o texto pelo texto, sem a correlação com o estudo dos elementos linguísticos e pragmáticos que lhe garantem estruturação e organicidade e lhe possibilitam interpretabilidade. Em outras, o foco maior está na metalinguagem, e os conteúdos são tratados de forma descontextualizada, fragmentada e, por isso, cansativa. As duas posturas quase sempre levam à aversão, pela maioria dos alunos, às aulas de Língua Portuguesa, pois as associam à veiculação de regras e "receitas" que, acreditam, nunca usarão. Como professores de língua materna, sabemos que uma mudança consistente nesse sentido não acontecerá repentinamente nem de qualquer maneira. É preciso que assumamos uma postura por meio da qual os sujeitos envolvidos nos processos comunicativos se apropriem da língua, percebendo-a em seu papel na interação verbal.

Nessa direção, a intervenção realizada baseou-se numa perspectiva funcional de ensino da língua, correlacionado os usos linguísticos às situações comunicativas em que eles se dão. Corresponde, em linhas gerais, ao que Travaglia (2002) chama de "ensino produtivo" da língua. O trabalho com o PR teve o texto como "pano de fundo" em todas as atividades desenvolvidas. Foram considerados e analisados usos canônicos e não canônicos desse elemento, associando-os a contextos formais e informais de 
interlocução. Contemplou-se, assim, a variação linguística, particularmente em relação às estratégias de relativização.

\section{Referências}

ANTUNES, I. Lutar com palavras: coesão e coerência. São Paulo: Parábola Editorial, 2005 .

BAGNO, M. Gramática pedagógica do português brasileiro. São Paulo: Parábola, 2011.

BECHARA, E. Moderna gramática portuguesa. 37. ed. rev., ampl. e atual. conforme o novo Acordo Ortográfico. Rio de Janeiro: Nova Fronteira, 2009.

BISPO, E. B. Orações relativas em perspectiva histórica: interface uso e cognição. Veredas, v. 18, n. 1, p. 222-235, 2014 a.

. Estratégias de relativização no PB: motivações discursivo-interacionais e cognitivas. In: BISPO, E. B.; OLIVEIRA, M. R. de (Orgs.). Orações relativas no português brasileiro: diferentes perspectivas. Niterói: Editora da UFF, 2014b, p.131-155.

. Estratégias de relativização no português brasileiro e implicações para o ensino: o caso das cortadoras. Tese (Doutorado em Estudos da Linguagem), Natal: UFRN, 2009. . Oração adjetiva cortadora: análise de ocorrências e implicações para o ensino de português. Linguagem E Ensino, v. 10, p. 163-186, 2007.

BRASIL, Secretaria de Educação Fundamental. Parâmetros Curriculares Nacionais: terceiro e quarto ciclos do ensino fundamental - língua portuguesa. Brasília/DF: $\mathrm{MEC} / \mathrm{SEF}, 1998$.

CASTILHO, A. T. de. Nova Gramática do Português Brasileiro. São Paulo: Contexto, 2010. DAMIANI, M. F. et al. Discutindo pesquisas do tipo intervenção pedagógica. Cadernos de Educação - FaE/UFPel. Pelotas, n. 45, p. 57-67, 2013.

DOLZ, J.; NOVERRAZ, M.; SCHNEUWLY, B. Sequências didáticas para o oral e a escrita: apresentação de um procedimento. In: DOLZ, J.; SCHNEUWLY, B. Gêneros orais e escritos na escola. [Tradução e organização: Roxane Rojo e Glaís Sales Cordeiro]. Campinas, SP: Mercado das Letras, 2004, p. 96-128. 
DU BOIS, J. W. Competing motivations. In: HAIMAN, J. (ed.). Iconicity in syntax. Amsterdam: John Benjamins, 1985, p. 343-365.

FURTADO DA CUNHA, M. A.; TAVARES, M. A. Funcionalismo e ensino de gramática. 2 ed. Natal: EDUFRN, 2016.

FURTADO DA CUNHA, M. A.; COSTA, M. A.; CEZARIO, M. M. Pressupostos teóricos fundamentais. In: FURTADO DA CUNHA, M. A.; OLIVEIRA, M. R. de; MATELOTTA, M. E. (Orgs.). Linguística funcional: teoria e prática. São Paulo: Parábola Editorial, 2015, p. 21-47.

FURTADO DA CUNHA, M. A.; BISPO, E. B; SILVA. J. R. Linguística funcional centrada no uso e ensino de português. Gragoatá, n. 36, p. 80-104, 2014.

GIVÓN, T. Functionalism and grammar. Amsterdan: John Benjamins, 1995.

.Syntax: a functional-typological introduction. v. II, Amsterdam: John Benjamins, 1990.

Syntax: a functional-typological introduction. v. I, Amsterdam: John Benjamins, 1984 .

KENEDY, E. Estruturas sintáticas de orações relativas. In: BISPO, E. B.; OLIVEIRA, M. R. de (Orgs.). Orações relativas no português brasileiro: diferentes perspectivas. Niterói: Editora da UFF, 2014, p. 11-46.

LEAL, C. A. Vamos brincar de quê? Os jogos cooperativos no ensino de ciências. Dissertação (Mestrado Profissional em Ensino de Ciências), Rio de Janeiro: IFRJ, 2013. MARTELOTTA. M. E. Mudança linguística: uma abordagem baseada no uso. São Paulo: Cortez, 2011.

OLIVEIRA. M. R. de; WILSON, V. Linguística funcional aplicada ao ensino do português. In: FURTADO DA CUNHA, M. A.; OLIVEIRA, M. R. de; MATELOTTA, M. E. (Orgs.). Linguística funcional: teoria e prática. São Paulo: Parábola Editorial, 2015, p. 79-110. .$;$ Linguística e ensino. In: MARTELOTTA, M. E. (org.). Manual de linguística. São Paulo: Contexto, 2008, p. 235-242.

OLIVEIRA, M. R. de; CEZARIO, M. M. PCN à luz do funcionalismo linguístico. Linguagem E Ensino, v. 10, p. 87-108, 2007.

SLOBIN, D. I. Psicolinguística. São Paulo: Editora Nacional/EDUSP, 1980.

THIOLLENT, M. Metodologia da pesquisa-ação. 18 ed. São Paulo: Editora Cortez, 2011. 
TRAVAGLIA, L. C. Gramática e interação: uma proposta para o ensino de gramática no $1^{\circ}$ e 2o graus. 8 ed. São Paulo: Cortez, 2002.

\section{Anexos}

\section{ANEXO I - Atividade 2}

Produção de texto: Artigo de opinião

O filme Que horas ela volta?, a partir de certo momento, apresenta a filha de Val determinada a entrar para a Faculdade de Arquitetura e Urbanismo de São Paulo - FAU, para cursar Arquitetura, o que choca os patrões pelo fato de que o filho deles também vai fazer o mesmo vestibular. Em uma das falas da patroa, fica bem clara a ideia de que seria impossível para Jéssica, menina pobre, filha da empregada, estudante de escola pública no Nordeste, ter sucesso.

Reflita sobre o que viu no filme e apoie-se nas ideias socializadas por seus colegas no momento da discussão para escrever um artigo de opinião, apresentando seu ponto de vista acerca da seguinte questão: "É possível um estudante pobre, de escola pública, ingressar em uma universidade conceituada, para fazer um curso considerado de elite?"

Obs.: Seu texto deve ter, no mínimo 20 e no máximo 30 linhas, e obedecer à estrutura característica do gênero.

\section{ANEXO II - Atividade 3}

\section{Exercício I}

Nos trechos a seguir (todos coletados de resenhas e comentários sobre o filme Que horas ela volta?, na mídia), foram suprimidas algumas palavras, propositalmente. Sua tarefa será preencher cada espaço vazio com uma palavra que julgar adequada.

a) "Regina Casé demonstra seu talento de atriz no papel de Val, empregada trabalha há anos para uma família de elite em São Paulo. Ela não vê sua filha há uma década, e Val inconscientemente a substituiu pelo adolescente ajudou a criar como doméstica (daí o título em inglês do filme, "a segunda mãe"). (...)"

\section{(Marcelo Hessel)}

(Fonte: https://omelete.uol.com.br/filmes/criticas/que-horas-ela-volta/ Acesso em 10/o8/2017)

b) "Ela trabalha como empregada doméstica na casa do casal Carlos (Lourenço Mutarelli) e Bárbara (Karine Teles). Nessa residência ela faz de tudo: lava, cozinha, põe a mesa, retira os 
pratos, além de cuidar de Fabinho (Michel Joelsas) ela dispensa todo carinho de mãe, já que, foi obrigada a deixar sua única filha no Nordeste.”

(Gio Souza)

(Fonte: https://atraidospelaleitura.wordpress.com/que-horas-ela-volta/. Acesso em 10/o8/2017)

c) "Ainda não vi esse filme, mas já participei da "realidade" ele retrata e confesso que fiquei espantada em ver que os empregados eram "estranhos" na casa das pessoas. (...) Quando fui morar com mio amore a moça trabalhava na casa não se sentava a mesa com a gente. Foi muito difícil mudar isso. Ela me dizia que sabia o seu "lugar". Acho certas coisas estranhíssimas...”

\section{(Lunna Guedes - Comentário)}

(Fonte: https://atraidospelaleitura.wordpress.com/que-horas-ela-volta/. Acesso em 10/o8/2017)

d) "Então... mas tomando por base o "meu" comportamento enquanto hospede: Não escolho onde prefiro ficar, não vou mexer em uma prateleira e tirar um livro, nunca (jamais) aceitaria ser servida por uma pessoa está saindo para trabalhar, em geral respondo "não obrigada" para as coisas claramente estão me sendo servidas por educação.(...)"

\section{(Luana Palhares - Comentário)}

(Fonte: https://atraidospelaleitura.wordpress.com/que-horas-ela-volta/. Acesso em 10/o8/2017.

$$
\text { Adaptado) }
$$

e) "Um dos grandes méritos deste roteiro, também assinado por Anna, é a capacidade de articular vários planos de uma mesma situação e multiplicar os olhares sobre ela. Assim, elege como sua protagonista a doméstica Val (Regina Casé), uma pernambucana há vários anos trabalha como babá e empregada na casa de uma família de classe média alta em São Paulo. Ou seja, assume o ponto de vista de alguém ocupa o andar de baixo, literal e metaforicamente, na trama."

$$
\text { (Resumo - por Neusa Barbosa) }
$$

(Fonte:https://br.noticias.yahoo.com/estreia-que-horas-ela-volta-explora-contradicoes-universo.html/. Acesso em 08/o8/2017)

1. Observe, nos trechos de $a$ ) a $e$ ), a palavra que vem antes do espaço preenchido por você. Qual é essa palavra e a que classe gramatical pertence? 
2. Em relação aos trechos anterior e posterior ao espaço preenchido em cada texto, qual a finalidade da palavra que você usou no preenchimento, isto é, qual a serventia dessa palavra no espaço em que foi inserida? Elabore uma explicação.

3. Você acha mesmo necessário o preenchimento dos espaços em questão? Se não fossem preenchidos com a palavra escolhida por você, ou seja, se eles ficassem vazios, o que aconteceria no que se refere à compreensão de cada texto? Apresente uma justificativa para suas respostas. 4. Você percebeu a possibilidade de, em algum(ns) trecho(s), ser usada outra palavra que fizesse o mesmo efeito? Em que trecho(s) isso seria possível e que palavra(s) você usaria?

\section{Exercício II}

Leia atentamente os trechos de resenhas do filme, coletados de blogs de críticos culturais.

A. "Durante pelo menos meia hora de filme, acompanhamos o dia-a-dia de Val, que abdicou do convívio da filha Jéssica, que ficou com sua família no Nordeste, e mora na casa dos patrões. As cenas são diretas e ela acaba quase sempre engolida pelo cenário, muito limpo e muito grande; pela rotina circular; e pelo tratamento frio, mas não muito da patroa, inconscientemente camuflado em pequenos afagos e elogios. Seu bálsamo é Fabinho, "menino mais bonito não tem no Brasil", que ajudou a criar e que trata com beijos e cafunés."

(Fonte: http://filmesdochico.uol.com.br/que-horas-ela-volta/. Acesso em 10/o8/17)

B. "De todo modo, ela (Jéssica) não era bem-vinda ali; seu lugar naquela casa era incerto ou, pior, de rejeição. Para a patroa Bárbara, uma intrusa; para o patrão Carlos, quase como uma sinhazinha de quem ele se sentia no direito de abusar; para Fabinho, uma espécie de concorrente (não se esqueçam de sua defensiva "Eu também gosto de ler", ao notar que Jéssica entendia muito mais dos livros que ele próprio); para Val, um fardo, na medida em que a filha expunha a precariedade das condições de vida da própria mãe.

(Fonte:https://ensaiosdegenero.wordpress.com. Acesso em 10/o8/2017)

C. Com um olhar crítico para a sociedade brasileira dos nossos dias, a trama tem como foco central a vida da empregada doméstica Val, interpretada com brilhantismo por Regina Casé, uma pernambucana que deixou a filha com a irmã e veio tentar a sorte em São Paulo. Ela trabalha numa mansão no Morumbi, onde além de todos os afazeres domésticos é babá de Fabinho (vivido por Michel Joelsas já adolescente). 
(Fonte: http://favodomellone.com.br/que-horas-ela-vota-filme-tem-olhar-critico-a-sociedadecontemporanea/. Acesso em 10/o8/2017)

Observe os trechos das colunas a seguir.

COLUNA 1

a) Durante pelo menos meia hora de filme, acompanhamos o dia-a-dia de Val. Val abdicou do convívio da filha Jéssica. Jéssica ficou com sua família no Nordeste.

c) Seu bálsamo é Fabinho. Ajudou a criar Fabinho. Trata Fabinho com beijos e cafunés.

e) Para a patroa Bárbara, uma intrusa; para o patrão Carlos, quase como uma sinhazinha. O patrão se sentia no direito de abusar da sinhazinha.

g) Ela trabalha numa mansão no Morumbi. Na mansão, além de todos os afazeres domésticos é babá de Fabinho.
COLUNA 2

b) "Durante pelo menos meia hora de filme, acompanhamos o dia-a-dia de Val, que abdicou do convívio da filha Jéssica, que ficou com sua família no Nordeste..."

d) "Seu bálsamo é Fabinho, (...), que ajudou a criar e que trata com beijos e cafunés."

f) "Para a patroa Bárbara, uma intrusa; para o patrão Carlos, quase como uma sinhazinha de quem ele se sentia no direito de abusar [...]"

h) "Ela trabalha numa mansão no Morumbi, onde além de todos os afazeres domésticos é babá de Fabinho [...]"

1. Comparando os trechos da coluna 1 (modificados pela professora) com os da coluna 2 (originais), que diferença você percebe na estrutura de cada um deles?

2. A diferença que você percebeu interfere na compreensão da ideia veiculada? Em alguma das colunas os textos são compreendidos mais rapidamente? Justifique.

3. E quanto ao sentido, você percebeu alguma alteração entre os textos das duas colunas?

Comente.

\section{Exercício III}

Leia com atenção as duas orações (períodos simples) abaixo. Veja que na segunda se repete um termo da primeira.

$1^{\underline{a}}$ oração: Na casa dos patrões havia uma bonita piscina.

$2^{2}$ oração: A piscina estava sempre iluminada.

Juntando as duas orações por meio de uma palavra específica, o termo repetido na segunda oração desapareceu, e o período ficou assim:

Na casa dos patrões havia uma piscina / que estava sempre iluminada.

$$
1^{\mathrm{a}} \text { oração } \quad 2^{\underline{a}} \text { oração }
$$


1. Sua primeira tarefa é continuar juntando a segunda oração à primeira para formar um período composto. Observe como aconteceu no modelo, encontre uma palavra específica para cada situação e escreva sua versão.

a) Na casa dos patrões havia uma bonita piscina. Fabinho e os amigos sempre tomavam banho na piscina.

b) Na casa dos patrões havia uma bonita piscina. Val nunca entrou na piscina.

c) Na casa dos patrões havia uma bonita piscina. Jéssica gostou muito da piscina.

d) Fabinho estava sempre com Val. Val o tratava com carinho materno.

e) Fabinho estava sempre com Val. Ele gostava de conversar com Val.

f) Val estava sempre defendendo Fabinho. Ela morria de amores por Fabinho.

2. Com base no que fez no exercício anterior, responda:

a) Você teve dificuldades para resolver esse exercício? Por quê?

b) Ao juntar as orações, você percebeu se havia mais de uma possibilidade de ligação, ou seja, havia outra palavra que servisse para ligar as orações no período? Apresente as opções percebidas por você para cada situação.

c) Como foi dito no início deste exercício, a palavra escolhida para juntar as orações evitaria que um termo da primeira oração fosse repetido na segunda. Você percebeu se em alguma situação houve a necessidade de usar uma preposição antes da palavra que você escolheu para evitar a repetição? Comente.

d) Como você avalia a nova estrutura (formada por você), após juntar as orações no período composto? O novo período formado ficou mais fácil de ser compreendido ou você não percebeu diferença entre as duas estruturas? Justifique sua resposta.

\section{Exercício IV}

Neste exercício você deve reescrever o texto de forma que substitua a palavra QUE, em algumas ocorrências, por meio de outros recursos linguísticos que lhe possibilitem um novo texto com o mesmo sentido do primeiro. Faça as alterações necessárias. 
Bárbara, que é uma estilista conceituada, é casada com Carlos, que é um artista plástico que vive doente e desanimado. A relação que eles vivem já não era boa, e ficou consideravelmente pior com a chegada de Jéssica, a filha que Val deixou no Nordeste, com os familiares. O filho do casal, Fabinho, que é um adolescente problemático, foi “criado” pela empregada, que cuida dele como se fosse seu filho.

Agora responda:

1. Você considerou a atividade difícil? Por quê?

2. Ao substituir a palavra QUE por outra construção, logicamente a estrutura do texto mudou.

a) Na sua opinião, essa mudança beneficia ou prejudica a compreensão do texto pelos leitores? Explique.

b) Houve alteração de sentido na versão produzida por você em relação ao texto original? Diga o que você percebeu e comente.

$\mathrm{ANEXO}_{3}$ - Atividade 4: Comparação entre diferentes estratégias de relativização

A dúvida

Certo dia, numa aula em que a professora aplicava algumas atividades sobre o filme Que horas ela volta?, ao qual tinha assistido com os alunos, ela coloca para eles um exercício em que deveriam transformar dois períodos simples em um período composto. Para isso eles teriam que encontrar maneiras diferentes, isto é, as respostas não poderiam se repetir. A professora anotaria cada resposta no quadro. Ela então apresentou o seguinte enunciado básico: “Bárbara explorava Val. O prazer de Val era cuidar de Fabinho, filho da patroa".

Passados alguns minutos, uma garota bem espevitada que sentava na frente levantou a mão e disse, com ar de quem sabe tudo, que havia duas possibilidades:

- Bárbara explorava Val, que ela tinha o prazer de cuidar de Fabinho, filho da patroa. E Bárbara explorava Val, que o prazer era cuidar de Fabinho, filho da patroa.

Outra menina, para desbancar a colega:

- Professora, é assim: Bárbara explorava Val, que o prazer dela era cuidar de Fabinho, filho da patroa.

Assim que a professora terminou de anotar a segunda resposta no quadro, ouve-se a voz do novato, que ficava o tempo todo calado no fundo da sala: 
- Professora, a maneira certa é esta: Bárbara explorava Val, cujo prazer era cuidar de Fabinho, filho da patroa.

A turma toda se espantou ao ver que o garoto novato se revelou. Foi então que outro aluno fez a pergunta:

- E aí, professora, como é que se diz? Fiquei bolado nessa... numa dúvida cruel. E eu gosto de saber as respostas. Me ajude, por favor!

(Tocou o sinal.)

(Texto criado por Maria Estela Lima da Costa Amurim, em 14/o8/17, especialmente para esta atividade.)

- Resolvemos que é você quem vai ajudar o garoto duvidoso na próxima aula. Para ficar mais “esperto", reflita sobre as questões seguintes e prepare-se, pois o colega é curioso!

1. Das estruturas elaboradas pelos alunos, qual você considera mais fácil de ser compreendida? Por quê?

2. Qual delas você teria usado como resposta se fosse um dos três alunos que falaram? Por qual razão você a usaria?

3. A resposta do novato estava realmente certa? Por que será que ele fez essa observação a respeito da resposta que deu à professora? Comente.

4. Na sua opinião, ao mudar as estruturas, o sentido do primeiro enunciado (da professora) se perdeu? Comente.

5. Você teria outra maneira de responder à questão posta pela professora? Apresente-a.

\footnotetext{
* Professor Associado da Universidade Federal do Rio Grande do Norte, Campus de Natal, onde atua nas áreas de Língua Portuguesa, na graduação, e de Linguística, na pós-graduação. Pesquisador do Grupo de Estudos Discurso \& Gramática.

** Mestra em Letras pelo Mestrado Profissional em Letras (PROFLETRAS), UFRN. Professora da Rede Estadual de Ensino do Rio Grande do Norte.
} 